\title{
FILAGGRIN AND CYTOKINES IN RESPIRATORY SAMPLES OF PRETERM INFANTS AT VIRAL RESPIRATORY INFECTION RISK
}

Jose Manuel Rodrigo-Muñoz ${ }^{1}$, Beatriz Sastre ${ }^{1}$, Laura Sánchez-García ${ }^{2}$, Maria Luz Garcia-Garcia $^{3}$, Adelina Pellicer ${ }^{2}$, Ersilia González-Carrasco ${ }^{3}$, Celia Fabra², Marta Gil-Martinez $^{1}$, Clara Lorente-Sorolla ${ }^{1}$, Raquel Garcia-Latorre ${ }^{1}$, Sonia Alcolea ${ }^{2}$, Inmaculada Casas $^{4}$, Cristina Calvo ${ }^{2}$, and Victoria Pozo ${ }^{1}$

${ }^{1}$ Instituto de Investigacion Sanitaria de la Fundacion Jimenez Diaz

${ }^{2}$ Hospital Universitario La Paz

${ }^{3}$ Hospital Universitario Severo Ochoa

${ }^{4}$ National Microbiology Center (ISCIII)

January 20, 2022

\begin{abstract}
Background: Respiratory viral infections (RVIs) are frequent in preterm infants and may have long-term impact on respiratory morbidity, especially those with bronchopulmonary dysplasia (BDP). The immune response and respiratory are key defence elements, so the purpose of this study is to evaluate the immune response regulation and the respiratory epithelial barrier integrity in the preterm infants suffering RVIs during Neonatal Intensive Care Unit (NICU) admission. Materials and methods: Nasopharyngeal aspirate (NPA) was obtained, separating cells from supernatants. Viral detection was performed by RTnested PCR, and gene expression by qPCR. Proteins were detected by western blot and ELISA or Luminex. Small airway epithelial cells (SAEC) were stimulated with Poly:IC and/or wounds. Results: Pre-infection samples from 26 preterm infants that later developed RVIs had less frequency of filaggrin gene expression and fewer protein levels compared to 23 noninfected controls. Conversely, filaggrin, IL-1 $\beta$, MIP-1 $\beta$, VEGF and HIF-1 $\alpha$ levels were higher in pre-infection supernatant samples, being infection-risk biomarkers. IL-17A, RANTES, VEGF, and HIF- $1 \alpha$ levels were higher during and post infection, while MCP-1 and amphiregulin were reduced after infection. Small airway epithelial cells (SAEC) stimulated by poly:IC reduced filaggrin gene expression and increased its levels at supernatant. Finally, poly:IC stimulation over SAEC increased TLR3 and TSLP expression, while reduced AREG. Conclusion: Filaggrin gene expression and protein quantity was reduced at cellular level of the NPA, while its secreted levels were increased in basal samples from infected newborns and in SAEC stimulated with poly:IC. Our findings highlight the importance of filaggrin as a factor facilitating RVIs.
\end{abstract}

\section{Hosted file}

RODRIGO-MU \selectlanguage\{ngerman\}ÑOZ ET AL.docx available at https://authorea.com/users/ 445628/articles/553417-filaggrin-and-cytokines-in-respiratory-samples-of-preterminfants-at-viral-respiratory-infection-risk 

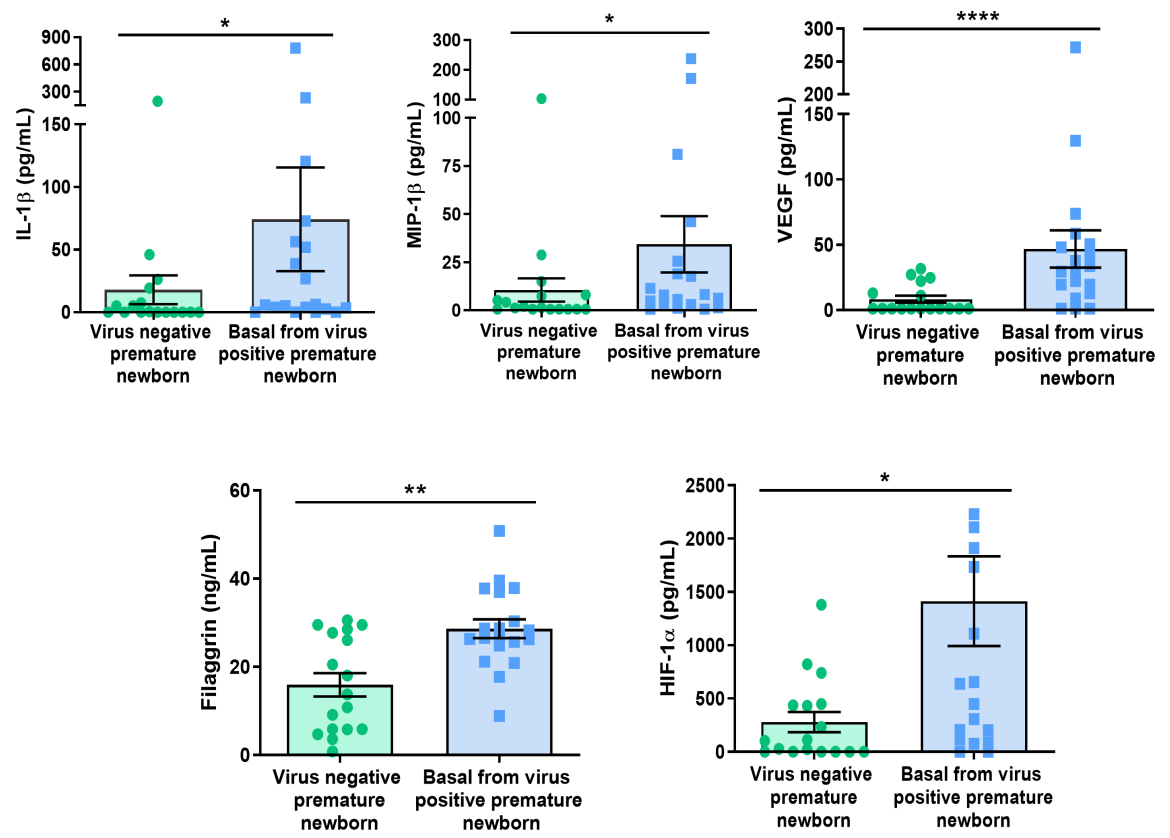

MIP-1 $\beta$ ROC curve for viral infection predisposition

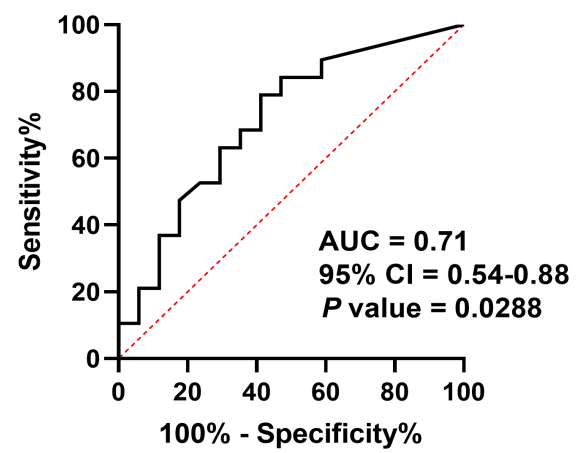

\section{VEGF ROC curve for viral infection predisposition}

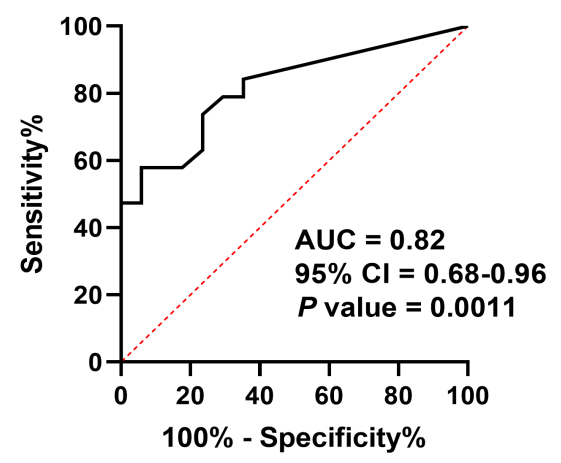

\section{Filaggrin ROC curve for viral infection predisposition}

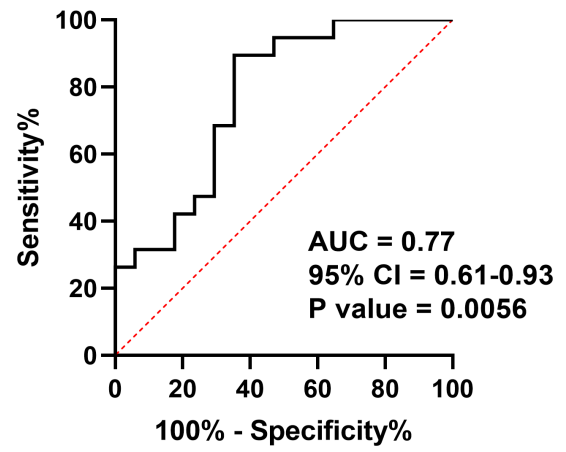

HIF-1 $\alpha$ ROC curve for viral infection predisposition

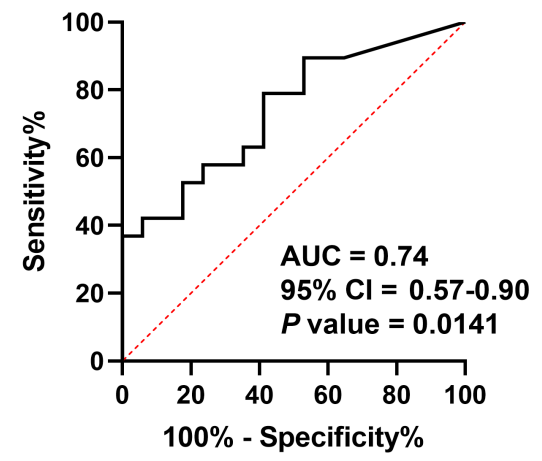


(A)
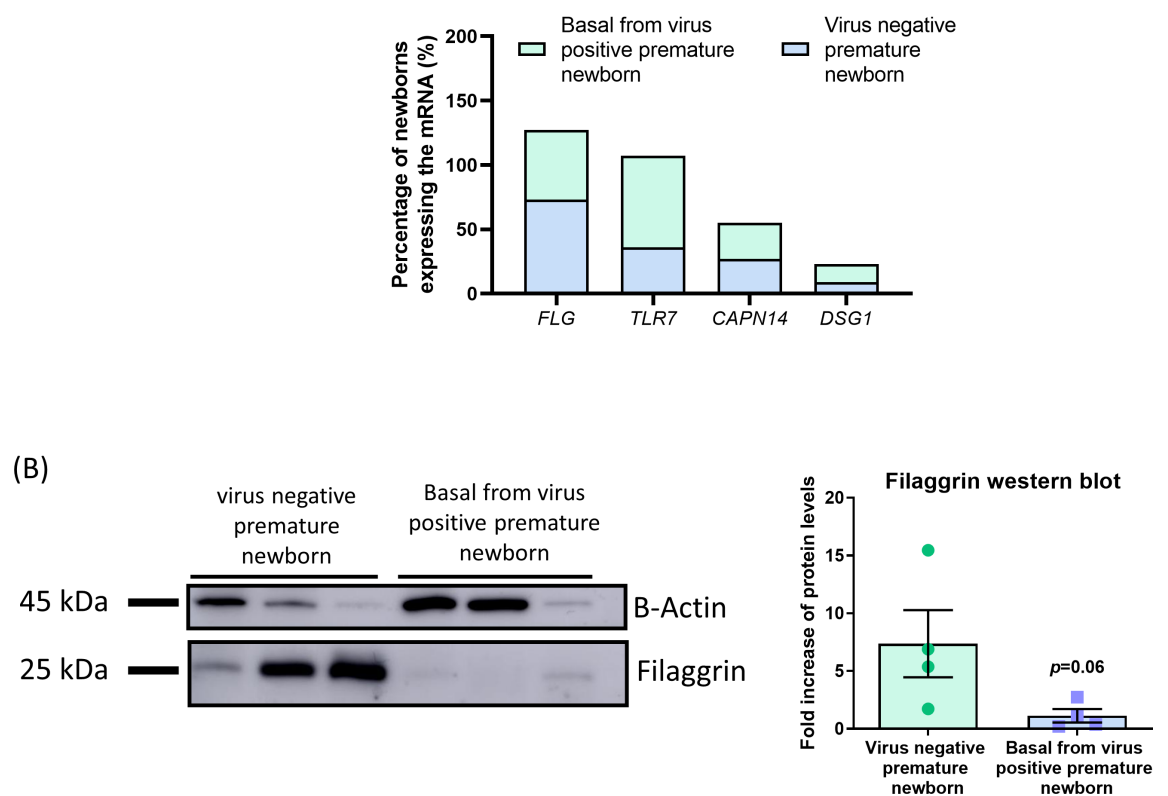

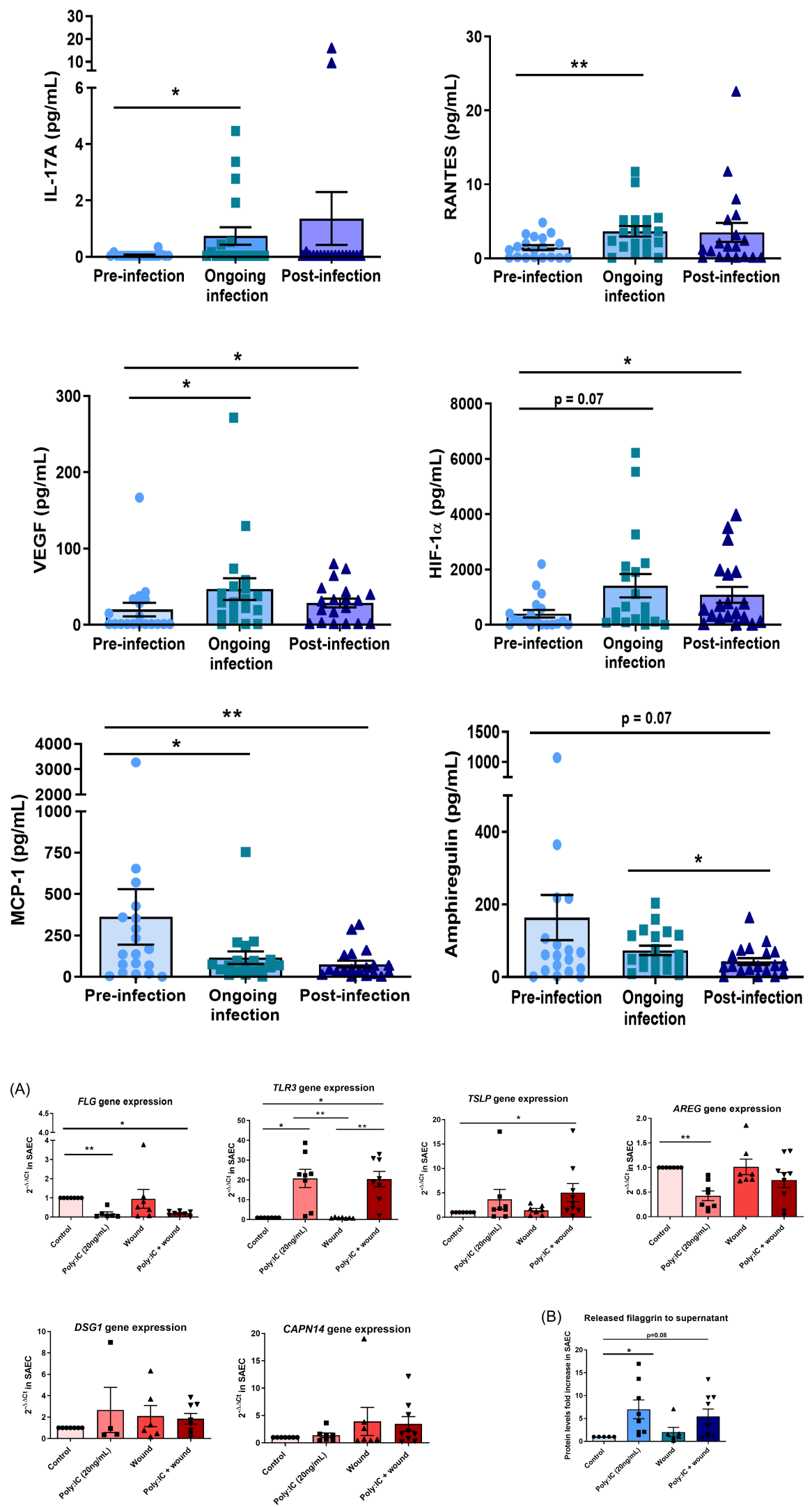